\title{
Associations between sleeping habits and food consumption patterns among 10-11-year-old children in Finland
}

\author{
Lisa Westerlund ${ }^{1}$, Carola Ray ${ }^{1,2}$ and Eva Roos ${ }^{1,2} *$ \\ ${ }^{1}$ Folkhälsan Research Center, Paasikivenkatu 4, 00250 Helsinki, Finland \\ ${ }^{2}$ Department of Public Health, University of Helsinki, O0014 Helsinki, Finland \\ (Received 2 October 2008 - Revised 13 May 2009 - Accepted 21 May 2009 - First published online 7 August 2009)
}

The increasing prevalence of overweight and obesity among children is of special concern. Inverse associations between sleep length and overweight have been found in children. Short sleeping hours result in hormonal changes, which increase perceived hunger and appetite. This could affect food intake, and consequently lead to overweight. The aim is to find out whether there is an association between adequate sleep and food consumption among 10-11-year-old school children in Finland. One thousand two hundred and sixty-five children (response rate $79 \%$ ), aged 9-11, from thirty-one schools filled in a questionnaire about their health behaviour. Inadequate sleep was measured as short sleeping hours during school nights and weekend nights, difficulties in waking up in the morning and tiredness during the day. Food consumption patterns were measured by two consumption indices, energy-rich foods and nutrient-dense foods, based on a short FFQ (sixteen items). Inadequate sleep is associated with food consumption patterns. Boys with shorter sleep duration during school nights, and who were felt tired during the day, were more likely to consume energy-rich foods. Girls with shorter sleep duration during school nights consumed more likely energy-rich foods and less likely nutrient-dense foods. Adjusting for physical activity and screen time weakened the explored associations. The associations with energy-rich foods were stronger for boys than for girls. Sleeping habits are associated with food consumption patterns. Shorter sleep duration during school nights in school children is associated with higher consumption of energy-rich foods.

\section{Sleep: Food consumption: Children}

Overweight and obesity have increased globally during the last decade and have now reached epidemic proportions. The increasing prevalence of overweight and obesity among children is of special concern, since it predicts obesity in adult age ${ }^{(1)}$. Solutions as to how to stop this trend have been sought in a number of fields, and lately attention has been paid to sleeping habits and length of sleep. Inverse associations between sleep length and overweight have been found in several studies and reviews, both in adults and children ${ }^{(2-9)}$. Few studies exploring the mechanisms behind this association have been conducted, and we need more knowledge on how this association can be explained.

According to Patel \& $\mathrm{Hu}^{(5)}$, a number of causal pathways linking short sleep duration with obesity have been suggested based on experimental studies of sleep deprivation. Sleep deprivation might increase caloric intake either by increased hunger or increased opportunities to eat. Short sleeping hours result in several hormonal changes ${ }^{(10-12)}$. A decrease in nocturnal levels of the anabolic, lipolysis-maintaining growth hormone has been observed in the absence of sleep ${ }^{(13)}$. Decrease in growth hormone could theoretically lead to overweight due to decreased nocturnal lipolysis. Sleep restriction also decreases circulating levels of the appetite-suppressing hormone leptin, and increases levels of the appetite-stimulating hormone ghrelin ${ }^{(12,14)}$. Experiments have shown that both appetite and hunger scores are elevated by sleep deprivation and the increases were particularly noted for high fat and high carbohydrate foods ${ }^{(15)}$. This increase in appetite could theoretically lead to changes in food intake, especially increased intake in high fat and high carbohydrate foods, and consequently lead to overweight due to increased energy intake.

Overweight is a direct effect of energy intake exceeding energy expenditure. Since food choice and consumption play a central role in energy intake, it is of interest to study which mechanisms affect these behavioural patterns. Food choice might be influenced by sleeping habits, as well as by other lifestyle-related factors ${ }^{(16,17)}$. Sex is also a factor that affects food choice and should be taken into account ${ }^{(18)}$. Girls tend to consume fruit and vegetables more frequently than boys. Boys, on the other hand, drink milk more often, but also consume fast food and unhealthy snacks more often than girls ${ }^{(16)}$.

Since sleep requirement varies among individuals, sleep length is not the only way to measure adequate sleep. Previous studies have also included other measures reflecting sleep status, such as difficulties waking up in the morning and tiredness during the day ${ }^{(19,20)}$. Previous research has shown that 
sleep duration during school nights is shorter than during weekend nights and sleep duration during school nights has a stronger association with weight than sleep duration during weekend nights ${ }^{(9)}$. Sleep duration during school nights and weekend nights may therefore have different relationships also with food intake.

If sleep length influences food choice and meal pattern, this could serve as one plausible mechanism behind the existing association between short sleeping hours and overweight. The aim of the present study is to find out whether there is an association between adequate sleep and food choice among 10-11-year-old school children in Finland.

The research questions are:

1. Is there an association between sleep length during week, during school nights and weekend nights, difficulty waking up in the morning or tiredness during the day and food consumption patterns in school aged children?

2. Are these associations different for boys and girls?

The hypothesis is that inadequate sleep associates with more frequent consumption of foods with high-energy density.

\section{Material and methods}

The present study was conducted according to the guidelines laid down in the Declaration of Helsinki and all procedures involving human subjects were approved by the ethical committee at the Department of Public Health, University of Helsinki. Written informed consent was obtained from all subjects.

The study was a part of a school health promotion research project 'Health workshop' conducted by Folkhälsan Research Center, focusing on the health behaviour of school children in Swedish speaking schools in southern Finland. Baseline data used in the present study was collected in during years 2006.

\section{Participants}

In autumn 2006, 1265 children (616 girls and 649 boys), aged $9-11$, from thirty-one schools in southern Finland, filled in a questionnaire about their health behaviour in a supervised classroom situation. The response rate was $79 \%$.

\section{Measures}

Part of the questionnaire focused on sleeping habits, including bedtime, wake-up time, difficulties getting up in the morning and feelings of tiredness during the day. Bedtime and wake-up time were asked separately for school nights and weekend nights. It also contained a short FFQ including sixteen groups of food items and questions on physical activity and screen time.

Answering alternatives for bedtime and wake-up time were listed with half hour intervals. Bedtimes were ranging from 20.00 to 24.00 hours or later on school nights, and from 20.30 to 24.00 hours or later on weekend nights. Wake-up times ranged from 06.00 to 10.00 hours or later on school nights and 06.30 to 10.00 hours or later on weekend nights. Sleeping time was calculated on the basis of reported bedtime and wake-up time on school nights and weekend nights separately. Also an average daily sleeping time for a 7-d period was calculated from sleeping time during school nights and weekend nights according to the formula: $(5 \times$ sleep length on school days $+2 \times$ sleep length on weekend nights $) / 7$. Answering alternatives for how often the children reported difficulty waking up in the morning and tiredness during day were often (5-7 times/week), sometimes (2-4 times/week) and seldom (0-1 times/week).

The sixteen groups of food items included in the FFQ were: fruit or berries; fresh vegetables; cooked vegetables; milk; juice; coca cola or other soft drinks; juice drinks; hamburgers, hot dogs or meat pastry; pizza; crisps or popcorn; cookies; ice cream; sweets or chocolate; yoghurt or pudding; sweetened breakfast cereal or sweetened muesli; rye bread. Each group of food items was scored according to how often food items from the group were consumed per week: never $=0 \mathrm{p}$, less than once a week $=0.5 \mathrm{p}$, once a week $=1 \mathrm{p}, 2-4$ times/ week $=3 \mathrm{p}, 5-6$ times $/$ week $=5.5 \mathrm{p}$, once a day $=7 \mathrm{p}$ and several times a day $=14 \mathrm{p}$.

We also include in the analyses possible confounders, physical activity and screen time. Physical activity was asked as how many minutes he/she is active during normal school nights (five answer categories) and how many hours per week he/she is active during leisure time (six answer categories). Screen time was asked with two questions one focusing on how many hours daily watch TV, video or dvd and the other focusing on how many hours daily use computer or play Playstation Xbox or GameCube. The answer categories were seven, from not at all to $5 \mathrm{~h}$ or more per day.

\section{Data analysis}

All analyses were performed using the statistical package, SPSS version 17.0 (SPSS, Inc., Chicago, IL, USA).

A factor analysis, a principal component analysis, of food frequency intake data was conducted (Appendix 1) to find food consumption patterns among the children. Two dimensions were extracted from the rotated component matrix in the factor analysis. Both dimensions had eigenvalues exceeding 1. Based on these extracted dimensions, two food consumption pattern indices were constructed. A criterion for inclusion in the constructed indices was that the single group of food items had a value of 0.5 or more in the rotated component matrix. One index was labelled energy-rich foods, and included the following groups of food items: pizza; hamburgers, hot dogs or meat pastry; crisps or popcorn; cookies; ice cream; sweets or chocolate; coca cola or other soft drinks. The other index was labelled nutrient-dense foods, and contained the following groups of food items: fruits and berries; fresh vegetables; cooked vegetables; rye bread. The weekly consumption scores given for each group of food items were added up to form the new scores for the two indices.

Differences in sleep variables and food consumption patterns between sexes were analysed for continuous variables with Mann-Whitney's $U$ test and for categorical variables with $\chi^{2}$ test. The mixed models were used to examine the patterning of the continuous food consumption indices. These food consumption indices were used as dependent variables, while the sleep parameters, sleep length, difficulty waking up in the morning and tiredness during the day were used as 
separate independent variables. Grade level was controlled for in all models, sex was controlled in all models with total data. Physical activity and screen time were controlled for in models adjusting for possible confounders. Interactions between sex and the independent variables were computed for each dependent-independent variable analysis. The $\beta$-coefficient represents the difference in the mean frequency of consumption between the category of interest and the reference, which in the tables received the value 0 . For sleep length, the $\beta$-coefficient represents the addition for the mean frequency of consumption for each hour slept. Because the sample was collected in schools there is a possibility of school-clustering effect as the children are nested within schools. To account for the nested nature of the data, multilevel analyses were carried out for all analyses presented in Tables 2 and 3 .

\section{Results}

General characteristics of the study population are presented in Table 1 . The participants slept $9.8 \mathrm{~h}$ per night on average. The sleep length was longer during weekend nights than during school nights. Girls' sleep length was longer than boys' sleep length on weekend nights. Experiencing difficulty waking up in the morning often (5-7 times/week) was reported by $25 \%$, whereas only $7 \%$ reported that they often felt tired during the day. Difficulty getting up in the morning was more common among girls than boys and seldom or never being tired during the day was reported more often by boys. The score for energy-rich foods was on average $9 \cdot 25$, indicating a intake frequency of about 9 times/week, whereas the score nutrition-dense foods was 18.6, about 19 times/week. Boys had higher scores than girls for energy-rich foods, whereas girls had higher scores for nutrient-dense foods than boys.
Sleep length during school nights and for 7-d average was associated with consumption of energy-rich foods, no association with energy-rich foods was found for sleep length during weekend nights (Table 2). When examining the association between sleep length and consumption of energy-rich foods, we found a significant sex interaction for school nights $(P=0 \cdot 04)$ and for 7 -d average $(P=0 \cdot 03)$. Sleep length was negatively associated with energy-rich foods and this association was stronger for boys than for girls. Boys and girls getting a shorter night's sleep during school nights were more likely to consume energy-rich foods than ones getting a longer night's sleep.

A significant sex interaction between sleep length during school nights $(P=0.001)$ and 7 -d average $(P=0.006)$ and nutrient-dense foods was also found. In the sex-stratified analysis, sleep length during school days and 7-d average was positively associated with nutrient-dense foods among girls but not boys. Girls getting a longer night's sleep were more likely to consume food items included in the nutrientdense foods index compared with girls sleeping shorter hours (Table 2). No association was found for sleep length during weekend nights and nutrient-dense foods.

No sex interactions between difficulty waking up in the morning and food consumption were found. The more often the children reported difficulty waking up in the morning, the more frequently they consumed energy-rich foods, and less frequently nutrient-dense foods (Table 2).

A significant sex interaction $(P=0 \cdot 001)$ was found between tiredness during the day and energy-rich foods. Feeling tired during the day was associated with energy-rich foods. This association was stronger for boys than girls, although showing the same thing. Children, who more often felt tired during the day, were more likely to consume energy-rich foods, compared with their less tired counterparts. Feeling tired during the day was not associated with nutrient-dense foods, nor were any interactions found (Table 2).

Table 1. Description of sleep-related and diet-related factors among girls and boys

(Mean values and standard deviations or distribution and number of observations)

\begin{tabular}{|c|c|c|c|c|c|c|c|}
\hline & \multicolumn{2}{|c|}{ Total } & \multicolumn{2}{|c|}{ Girls } & \multicolumn{2}{|c|}{ Boys } & \multirow[b]{2}{*}{ Difference between sexes } \\
\hline & Mean & SD & Mean & SD & Mean & SD & \\
\hline \multicolumn{8}{|l|}{ Sleep length $(h)$} \\
\hline School days & 9.65 & 0.79 & 9.68 & 0.73 & 9.62 & 0.84 & NS \\
\hline Weekend nights & $10 \cdot 24$ & 1.03 & $10 \cdot 42$ & 0.95 & $10 \cdot 06$ & 1.08 & *** \\
\hline 7-d Average & $9 \cdot 82$ & 0.73 & $9 \cdot 89$ & 0.67 & $9 \cdot 74$ & 0.77 & 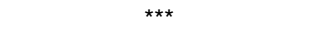 \\
\hline Do you have difficulty in waking up in the morning? & $\%$ & $n$ & $\%$ & $n$ & $\%$ & $n$ & $\star \star \star *$ \\
\hline Seldom or never (0-1 times/week) & 32 & & 26 & & 37 & & \\
\hline Sometimes (2-4 times/week & 44 & & 46 & & 42 & & \\
\hline \multirow[t]{2}{*}{ Often (5-7 times/week) } & 25 & & 28 & & 21 & & \\
\hline & 100 & 1232 & 100 & 606 & 100 & 626 & \\
\hline Do you feel tired during the day? & $\%$ & $n$ & $\%$ & $n$ & $\%$ & $n$ & * \\
\hline Seldom or never (0-1 times/week) & 55 & & 52 & & 58 & & \\
\hline Sometimes (2-4 times/week & 38 & & 42 & & 35 & & \\
\hline \multirow[t]{2}{*}{ Often (5-7 times/week) } & 7 & & 6 & & 8 & & \\
\hline & 100 & 1238 & 100 & 609 & 100 & 629 & \\
\hline \multicolumn{8}{|l|}{ Consumption (times/week) } \\
\hline Energy-rich foods & 9.25 & $9 \cdot 28$ & $7 \cdot 88$ & 6.09 & 10.58 & 11.41 & *** \\
\hline Nutrient-dense foods & $18 \cdot 66$ & 11.53 & $19 \cdot 42$ & 11.44 & 17.94 & 11.58 & * \\
\hline
\end{tabular}

Mean values or distributions were significantly different between sexes: ${ }^{\star} P \leq 0.05,{ }^{\star \star \star} P \leq 0 \cdot 001$. 
Table 2. Associations between sleep parameters and consumption frequency of energy-rich foods and nutrient-dense foods* ( $\beta$-Coefficient values of ANOVA and $95 \% \mathrm{Cl}$ )

\begin{tabular}{|c|c|c|c|c|c|c|c|c|c|}
\hline & \multicolumn{3}{|c|}{ Total $\dagger$} & \multicolumn{3}{|c|}{ Girlsł } & \multicolumn{3}{|c|}{ Boys $\ddagger$} \\
\hline & $P$ & $\begin{array}{c}\beta- \\
\text { Coefficient }\end{array}$ & $95 \% \mathrm{Cl}$ & $P$ & $\begin{array}{c}\beta- \\
\text { Coefficient }\end{array}$ & $95 \% \mathrm{Cl}$ & $P$ & $\begin{array}{c}\beta- \\
\text { Coefficient }\end{array}$ & $95 \% \mathrm{Cl}$ \\
\hline \multicolumn{10}{|l|}{ Energy-rich foods } \\
\hline Sleep length, school nights & $<0.001$ & -2.39 & $-3.09,-1.68$ & $<0.001$ & -1.45 & $-2.14,-0.75$ & $<0.001$ & -3.07 & $-4.22,-1.91$ \\
\hline Sleep length, weekend nights & $<0.001$ & -0.70 & $-1 \cdot 25,-0.16$ & 0.18 & -0.36 & $-0.89,0.17$ & 0.03 & -0.98 & $-1.87,-0.08$ \\
\hline Sleep length, 7-d average & $<0.001$ & -2.42 & $-3.19,-1.66$ & $<0.001$ & -1.42 & $-2.16,-0.67$ & $<0.001$ & $-3 \cdot 20$ & $-4.47,-1.93$ \\
\hline Difficulty wakening up & 0.008 & & & 0.21 & & & 0.04 & & \\
\hline Seldom (0-1 times/week) & & 0 & & & 0 & & & 0 & \\
\hline $\begin{array}{l}\text { Sometimes } \\
\quad(2-4 \text { times/week })\end{array}$ & & $0 \cdot 76$ & $-0.54,2.06$ & & 0.59 & $-0.66,1 \cdot 84$ & & 0.78 & $-1.43,2 \cdot 98$ \\
\hline Often (5-7 times/week) & & $2 \cdot 34$ & $0.84,3.83$ & & 1.23 & $-0 \cdot 14,2 \cdot 60$ & & 3.40 & $0.75,6.06$ \\
\hline $\begin{array}{l}\text { Tiredness during the day } \\
\text { Seldom (0-1 times/week) }\end{array}$ & $<0.001$ & & & 0.04 & & & $<0.001$ & & \\
\hline $\begin{array}{l}\text { Sometimes } \\
(2-4 \text { times/week })\end{array}$ & & $1 \cdot 21$ & $0.06,2.37$ & & 1.32 & $0.28,2 \cdot 36$ & & 1.06 & $-0.99,3.12$ \\
\hline \multicolumn{10}{|l|}{ Nutrient-dense foods } \\
\hline $\begin{array}{l}\text { Sleep length, scnool nignts } \\
\text { Sleekend nights }\end{array}$ & 0.46 & 0.24 & $-0.40,0.88$ & 0.57 & 0.28 & $\begin{array}{r}1.09,3.60 \\
-0.69,1.24\end{array}$ & 0.63 & $\begin{array}{r}-0.70 \\
0.21\end{array}$ & $\begin{array}{l}-1.83,0.43 \\
-0.65,1.08\end{array}$ \\
\hline Sleep length, 7-d average & $0 \cdot 17$ & 0.65 & $-0.27,1.57$ & 0.002 & $2 \cdot 14$ & $0.76,3.53$ & 0.46 & -0.47 & $-1.71,0.77$ \\
\hline Difficulty wakening up & 0.03 & & & 0.66 & & & 0.009 & & \\
\hline $\begin{array}{l}\text { Seldom }(0-1 \text { times/week }) \\
\text { Sometimes }\end{array}$ & & $\begin{array}{l}0 \\
-1 \cdot 76\end{array}$ & $-3.30,-0.23$ & & $\begin{array}{l}0 \\
-0 \cdot 18\end{array}$ & $-2.43,2.07$ & & $\begin{array}{l}0 \\
-3.08\end{array}$ & $-5 \cdot 18,-0.98$ \\
\hline Often (5-7 times/week) & & $-2 \cdot 15$ & $-3.92,-0.38$ & & -1.06 & $-3.56,1.44$ & & -2.96 & $-5.49,-0.42$ \\
\hline Tiredness during the day & 0.23 & & & 0.38 & & & 0.59 & & \\
\hline $\begin{array}{l}\text { Seldom }(0-1 \text { times/week }) \\
\text { Sometimes }(2-4\end{array}$ & & $\begin{array}{c}0 \\
-1 \cdot 13\end{array}$ & $-2.50,0.24$ & & $\begin{array}{c}0 \\
-1 \cdot 24\end{array}$ & $-3.14,0.66$ & & $\begin{array}{c}0 \\
-1.02\end{array}$ & $-3.02,0.98$ \\
\hline Often (5-7 times/week) & & $-1 \cdot 20$ & $-3.86,1.46$ & & -1.64 & $-5.60,2.32$ & & -0.86 & $-4.47,2 \cdot 76$ \\
\hline
\end{tabular}

* Multilevel analyses (mixed models) were carried out to taking into account the possibility of school-clustering effect.

$\dagger$ Sex and grade levels are controlled for in the model.

$\ddagger$ Grade level is controlled for in the sex-stratified model.

We further adjusted the models for physical activity and screen time. The associations between sleeping habits and food consumption patterns somewhat weakened for boys, but remained statistically significant for most associations (Table 3). For girls, the only associations that remained statistically significant was the association between sleep duration during school nights with energy-rich foods and sleep length during school nights and 7-d average with nutrient-dense foods.

\section{Discussion}

The present study showed that sleeping less during school nights is associated with food consumption patterns, more frequent consumption of energy-rich foods, such as fast foods and sweets, and lower consumption of nutrient-dense foods, such as fruits and vegetables. Sleeping less during school nights seems to have more negative implications for boys' food consumption patterns than for girls' food consumption patterns. Boys getting an inadequate sleep were more likely to consume energy-rich foods and less likely to consume nutrient-dense foods, than did girls with similar sleeping habits. On the other hand, girls seem to benefit more from sleeping longer. They were more likely to consume nutrient-dense foods the longer the sleep hours, whereas no such association was found for boys. Adjusting for physical activity and screen time weakened the association between sleeping habits and food consumption patterns.
Participation in the present study was voluntary, and a written consent both from the parents and the child was needed. This might have selected the children participating in the study towards more health conscious individuals, whereas the ones with a less healthy lifestyle might have chosen not to participate. A less selective data would probably have shown stronger associations than found in the present study.

We have used the same questions of sleep habits as in large cross-national studies, for example the cross-national research study Health Behaviour in School-aged Children, which is conducted in collaboration with the WHO Regional Office for Europe ${ }^{(21)}$ and the Pediatric Sleep Health Program ${ }^{(19)}$ conducted by Lifespan Sleep Disorders Center. The questions used in the questionnaire have not been validated. Because bedtime and wake-up time answering alternatives were with half hour intervals, sleep length could theoretically vary by as much as 59 min within the same sleep length value. This can affect the validity of the answers. In practice, the variation within the same sleep length value is more likely at most $30 \mathrm{~min}$.

The young age of the children participating in the study is another aspect that calls for attention. Are children aged 9-11 old enough to correctly assess their usual bedtime, wake-up time and food consumption rates in average, or do the answers mostly reflect the habits of the past few weeks? To ask the parents, as a more reliable source of information, to fill in the questionnaire on behalf of their children would have been an option. On the other hand, parents do 
Table 3. Associations between sleep parameters and consumption frequency of energy-rich foods and nutrient-dense foods* ( $\beta$-Coefficients of ANOVA, adjusted for physical activity and screen time, and $95 \% \mathrm{Cl}$ )

\begin{tabular}{|c|c|c|c|c|c|c|c|c|c|}
\hline & \multicolumn{3}{|c|}{ Total† } & \multicolumn{3}{|c|}{ Girlsł } & \multicolumn{3}{|c|}{ Boysł } \\
\hline & $P$ & $\begin{array}{c}\beta- \\
\text { Coefficient }\end{array}$ & $95 \% \mathrm{Cl}$ & $P$ & $\begin{array}{c}\beta- \\
\text { Coefficient }\end{array}$ & $95 \% \mathrm{Cl}$ & $P$ & $\begin{array}{c}\beta- \\
\text { Coefficient }\end{array}$ & $95 \% \mathrm{Cl}$ \\
\hline \multicolumn{10}{|l|}{ Energy-rich foods } \\
\hline Sleep length, school nights & 0.001 & -1.77 & $-2.48,-1.05$ & 0.04 & -0.74 & $-1.44,-0.03$ & 0.001 & -2.49 & $-3.68,-1.31$ \\
\hline Sleep length, weekend nights & 0.11 & -0.43 & $-0.97,0.10$ & 1.00 & 0.00 & $-0.51,0.51$ & 0.10 & -0.74 & $-1.63,0.15$ \\
\hline Sleep length, 7-d average & 0.001 & -1.75 & $-2.54,-0.97$ & 0.10 & -0.64 & $-1 \cdot 39,0 \cdot 12$ & 0.001 & -2.57 & $-3.88,-1 \cdot 27$ \\
\hline Difficulty wakening up & 0.12 & & & 0.38 & & & 0.19 & & \\
\hline Seldom (0-1 times/week) & & 0 & & & 0 & & & 0 & \\
\hline Sometimes (2-4 times/week) & & 0.53 & $-0.75,1.81$ & & 0.79 & $-0.39,1.98$ & & 0.19 & $-2 \cdot 02,2.40$ \\
\hline Often (5-7 times/week) & & 1.54 & $0.05,3.03$ & & 0.76 & $-0.56,2.08$ & & 2.32 & $-0.35,5 \cdot 00$ \\
\hline Tiredness during the day & 0.001 & & & 0.29 & & & 0.001 & & \\
\hline Seldom (0-1 times/week) & & 0 & & & 0 & & & 0 & \\
\hline Sometimes 2-4 times/week & & 0.79 & $-0.36,1.94$ & & 0.80 & $-0.21,1.81$ & & 0.73 & $-1 \cdot 35,2 \cdot 80$ \\
\hline Often 5-7 times/week & & 5.13 & $2 \cdot 92,7.34$ & & 0.13 & $-1.99,2 \cdot 26$ & & 8.85 & $5 \cdot 18,12.53$ \\
\hline \multicolumn{10}{|l|}{ Nutrient-dense foods } \\
\hline Sleep length, school nights & 0.76 & 0.13 & $-0.72,0.98$ & 0.005 & 1.91 & $0.59,3.24$ & 0.05 & $-1 \cdot 12$ & $-2.23,-0.01$ \\
\hline Sleep length, weekend nights & 0.98 & 0.01 & $-0.62,0.64$ & 0.98 & 0.02 & $-0.94,0.98$ & 0.98 & -0.01 & $-0.85,0.83$ \\
\hline Sleep length, 7-d average & 0.77 & 0.14 & $-0.79,1.06$ & 0.03 & 1.61 & $0.19,3.04$ & 0.13 & -0.94 & $-2 \cdot 16,0 \cdot 27$ \\
\hline Difficulty wakening up & 0.14 & & & 1.00 & & & 0.03 & & \\
\hline Seldom (0-1 times/week) & & 0 & & & 0 & & & 0 & \\
\hline Sometimes 2-4 times/week & & -1.51 & $-3.00,-0.02$ & & -0.09 & $-2 \cdot 29,2 \cdot 12$ & & $-2 \cdot 70$ & $-4.74,-0.67$ \\
\hline Often 5-7 times/week & & -0.89 & $-2.62,0.85$ & & -0.01 & $-2.48,2.46$ & & -1.57 & $-4.04,0.89$ \\
\hline Tiredness during the day & 0.84 & & & 0.98 & & & 0.79 & & \\
\hline Seldom (0-1 times/week) & & 0 & & & 0 & & & 0 & \\
\hline Sometimes $2-4$ times/week & & -0.06 & $-1.41,1.29$ & & -0.11 & $-2.00,1.78$ & & -0.07 & $-2.03,1.89$ \\
\hline Often 5-7 times/week & & 0.73 & $-1 \cdot 87,3.32$ & & 0.21 & $-3 \cdot 70,4 \cdot 12$ & & $1 \cdot 14$ & $-2 \cdot 36,4 \cdot 65$ \\
\hline
\end{tabular}

* Multilevel analyses (mixed models) were carried out to taking into account the possibility of school-clustering effect.

† Sex, grade level, physical activity and screen time are controlled for in the model.

$\ddagger$ Grade level, physical activity and screen time are controlled for in the sex-stratified model.

not necessarily know for example what their children eat during the day. A review article on child self-report $v$. parent-proxy report makes a case for the utility of child self-report ${ }^{(22)}$. Research demonstrates good reliability of health reports by children 8-11 years old, especially if the questionnaires were developed specifically for this age group.

To the present knowledge, only few studies have examined the association between adequate sleep and food habits or diet. One study on German children and adolescents showed no association between sleep duration and a nutrition quality score, which indicated the consumption of healthy and unhealthy foods ${ }^{(8)}$. Another study on Japanese school children showed that among boys sleepiness during daytime was associated with skipping breakfast and evening snack, whereas among girls sleepiness during daytime was associated with daily snacking ${ }^{(20)}$. One study on adolescents from Taiwan showed that adequate sleep was associated with adopting a healthy diet, including eating breakfast daily, eating three meals a day, drinking at least 1.5 litres water and choosing foods with little oil ${ }^{(17)}$. These studies have not carried out separate analyses for sleep duration during school nights and weekend nights. The results from previous studies are mainly in line with the present results, showing that inadequate sleep is associated with unhealthy food habits.

The plausible mechanisms behind the associations between sleeping habits and food consumption patterns are several, and it is possible that the mechanisms behind the associations between sleep inadequacy and energy-rich foods differ from the ones behind sleep adequacy and nutrient-dense foods. Hormonal changes due to short sleeping hours have been shown to increase perceived hunger and appetite ${ }^{(15)}$, and could therefore function as a plausible mechanism behind the observed association between sleep inadequacy and energy-rich foods. An irregular life style, including late bed times and irregular meal pattern, could also explain this association. Previous studies has shown that adequate sleep is associated with several other health-related behaviours and it has been suggested that inadequate sleep may be a screening indicator for unhealthy lifestyle ${ }^{(17)}$.

Different mechanisms for the association can perhaps explain the sex differences found in the present study. The mechanisms behind the associations between longer sleep and nutrient-dense foods among girls might be explained by upbringing and personal values. More research is needed on why this association was not found among boys. It is possible that diligent girls follow recommendations regarding a generally accepted lifestyle, both when it comes to sleep and nutrition. The association between sleep duration and energy-rich foods was stronger among boys. Also previous studies have found stronger association between sleep and BMI among male adolescents than among female adolescents and a suggested explanation for the sex differences is sex differences in the physiology, such as growth rates and hormone secretion during puberty ${ }^{(23)}$.

We found a stronger association with food consumption patterns for sleep duration of school nights compared with weekend nights. Also studies looking at the association between sleep duration and overweight have found stronger associations for sleep duration during school nights than for sleep duration during weekend nights ${ }^{(9)}$. School nights are for most school children shorter than weekend nights, because 
school children have to wake up early even after inadequate sleep. During weekends children usually sleep longer nights, because they wake up later in the morning, School nights, however, dominate the sleep length of children and daily routines during school days are therefore of special importance when promoting healthy lifestyle.

We also saw that adjusting for physical activity and screen time attenuated the association between inadequate sleep and food consumption patterns. In the analyses, physical activity was not independently associated with food consumption patterns, but screen time was (data not shown). It might be that screen time influences both on sleep duration and food consumption patterns and acts as a confounder. It is also possible that inadequate sleep increases the amount of screen time, which further has an impact on food consumption patterns by increased opportunities to eat ${ }^{(5)}$. In that case, screen time act as a mediator between sleep duration and food consumption patterns.

Further studies are needed to confirm the found associations, and more comprehensive dietary assessment methods and objective measures of sleep duration should be used, such as actigraphy ${ }^{(5)}$. More knowledge is needed on whether family rules and parents' support or meal patterns could explain the results. There is a possibility that that there is no causal association between sleeping habits and eating patterns. This is not possible to predict from these results, since this is a cross-sectional study; therefore, there is a need for studies with a cohort design and interventions to be able to confirm a causal association.

In the present study, we have controlled the analyses for sex, grade level, physical activity and screen time. The relatively small sample of the study limits the possibilities to control for a large number of factors. A larger sample would allow for multivariate analyses, which should include different socio-economic factors among others. Several studies have found associations between socio-economic status and vegetable consumption, food choice or meal pattern ${ }^{(16,18,24,25)}$.

\section{Conclusions}

The results from the present study show an association between inadequate sleep and more frequent consumption of energy-rich foods. Among girls, an association between longer sleeping time during school nights and consumption of nutrient-dense foods was also found. More research is needed to explain the association between sleeping time and food consumption and to explain why the associations are different depending on whether the sleep length is measured for school nights or for weekend nights. The results from the present study provide new knowledge of eventual mechanisms behind the association between inadequate sleep and overweight and obesity, and show that sleeping habits are associated with food consumption patterns and therefore diet might be a mediator for the associations between sleep and weight.

\section{Acknowledgements}

Statement reporting any conflicts of interest, funding and contribution of each author. We have no conflicts of interest.
The present work was supported by Samfundet Folkhälsan, Juho Vainio Foundation, Päivikki and Sakari Sohlberg Foundation, Signe och Ane Gyllenberg Foundation and Victoria Foundation. L. W. wrote and carried out the analyses of the first version of the submitted manuscript. E. R. and C. R. were responsible for the data collection and participated in the planning and writing of the manuscript. E. R. carried out further analyses and modified the text of the resubmitted versions. C. R. and L. W. participated in the planning of the resubmitted version. All authors have read and approved the present version of the manuscript.

\section{References}

1. Philippas NG \& Lo CW (2005) Childhood obesity: etiology, prevention and treatment. Nutr Clin Care 8, 77-88.

2. Locard E, Marvelle N, Billette A, et al. (1992) Risk factors of obesity in a five year old population: parental and environmental factors. Int J Obes 16, 721-729.

3. Sekine M, Yamagami T, Handa K, et al. (2002) A doseresponse relationship between short sleeping hours and childhood obesity: results of the Toyama Birth Cohort Study. Child Care Health Dev 28, 163-170.

4. Vioque J, Torres A \& Quiles J (2000) Time spent watching television, sleep regulation, and obesity in adults living in Valencia, Spain. Int J Obes 24, 1683-1688.

5. Patel SR \& Hu FB (2008) Short sleep duration and weight gain: a systematic review. Obesity 16, 643-653.

6. Padez C, Mourão I, Moreira P, et al. (2005) Prevalence and risk factors for overweight and obesity in Portuguese children. Acta Paediatr 94, 1550-1557.

7. Cappuccio FP, Taggart FM, Kandala N-B, et al. (2008) Metaanalysis of short sleep duration and obesity in children and adults. Sleep 31, 619-626.

8. Hitze B, Bosy-Westphal A, Bielfeldt F, et al. (2008) Determinants and impact of sleep duration in children and adolescents: data of the Kiel Obesity Prevention Study. Eur J Clin Nutr (Epublication 30 July 2008).

9. Seicean A, Redline S, Seicean S, et al. (2007) Association between short sleeping hours and overweight in adolescents: results from a US suburban high school survey. Sleep Breath 11, 285-293.

10. Tataranni PA, Larson D, Snitker S, et al. (1996) Effects of glucocorticoid on energy metabolism and food intake in humans. Am J Physiol 271, E317-E325.

11. Spiegel K, Leproult R \& Van Cauter E (1999) Impact of sleep debt on metabolic and endocrine function. Lancet 354, 1435-1439.

12. Schüssler P, Uhr M, Ising M, et al. (2005) Nocturnal ghrelin levels - relationship to sleep EEG, the levels of growth hormone, ACTH and cortisol - and gender differences. J Sleep Res 14, 329-336.

13. Sheen AJ, Byrne MM, Plat L, et al. (1996) Relationship between sleep quality and glucose regulation in normal humans. Am J Physiol 271, E261-E270.

14. Spiegel K, Leproult R, L'Hermite-Baleriaux M, et al. (2004) Leptin levels are dependent on sleep duration: relationships with sympathovagal balance, carbohydrate regulation, cortisol, and thyrotropin. J Clin Endocrinol Metab 89, 5762-5771.

15. Spiegel K, Tasall E, Penev P, et al. (2004) Brief communication: sleep curtailment in healthy young men is associated with decreased leptin levels, elevated ghrelin levels, increased hunger and appetite. Ann Intern Med 141, 846-850.

16. Roos EB, Karvonen S \& Rahkonen O (2004) Lifestyles, social background and eating patterns of 15 -year-old boys and girls in Finland. J Youth Studies 7, 331-349. 
17. Chen M-Y, Wang EK \& Jeng Y-J (2006) Adequate sleep among adolescents is positively associated with health status and health-related behaviors. BMC Public Health 6, 59.

18. Roos E, Lahelma E, Virtanen M, et al. (1998) Gender, socioeconomic status and family status as determinants of food behaviour. Soc Sci Med 46, 1519-1529.

19. The Pediatric Sleep Health Program. http://www.kidzzzsleep. org. http://www.kidzzzsleep.org/pdfs/SleepSelfReport_Child $\% 27$ sForm_-9-02.pdf (accessed June 2008).

20. Gaina A, Sekine M, Hamanishi S, et al. (2007) Daytime sleepiness and associated factors in Japanese school children. J Pediatr 151, 518-522.
21. Health Behaviour in School-aged Children, http://www.hbsc.org (accessed June 2008).

22. Riley A (2004) Evidence that school-age children can selfreport on their health. Ambul Pediatr 4, 371-376.

23. Knutson KL (2005) Sex differences in the association between sleep and body mass index in adolescents. J Pediatr 147, 830-834.

24. Roos E, Prättälä R, Lahelma E, et al. (1996) Modern and healthy? Socioeconomic differences in the quality of diet. Eur $J$ Clin Nutr 50, 753-760.

25. Keski-Rahkonen A, Kaprio J, Rissanen A, et al. (2003) Breakfast skipping and health-compromising behaviour in adolescents and adults. Eur J Clin Nutr 57, 842-853.

\section{Appendix 1.}

Extracted components from the rotated component matrix of the factor analysis, including all food groups used in the FFQ

\begin{tabular}{lrr}
\hline & Component 1 & Component 2 \\
\hline Fruit and berries & -0.057 & $0.682^{*}$ \\
Fresh vegetables & -0.084 & $0.782^{*}$ \\
Cooked vegetables & -0.001 & $0.676^{*}$ \\
Milk & 0.113 & 0.370 \\
Juice & 0.076 & 0.171 \\
Coca cola or other soft drinks & $0.587^{\star}$ & $-0 \cdot 107$ \\
Squash & 0.167 & 0.062 \\
Hamburgers, hot dogs or meat pastry & $0.728^{*}$ & -0.073 \\
Pizza & $0.667^{*}$ & -0.050 \\
Crisps or popcorn & $0.754^{*}$ & -0.021 \\
Cookies & $0.669^{*}$ & 0.096 \\
Ice cream & $0.664^{*}$ & 0.102 \\
Sweets or chocolate & $0.705^{\star}$ & -0.055 \\
Yoghurt or puddings & 0.242 & 0.253 \\
Sweetened breakfast cereal or sweetened muesli & 0.343 & 0.034 \\
Rye bread & -0.059 & $0.646^{*}$ \\
Eigenvalue & 3.766 & 2.426 \\
\hline
\end{tabular}

${ }^{*}$ Food groups with a value above 0.5 are included in the index. 